\title{
Probabilistic methods for prediction of corrosion in a service water system
}

\author{
E. Houston, G. Licina \& D. Dedhia \\ Structural Integrity Associates, Inc., USA
}

\begin{abstract}
Nuclear plant service water systems are a critical part of the facility's infrastructure. System integrity and performance are vital for plant reliability and essential to achieving a plant life of 40 years and beyond. The low temperature and pressure service water piping systems are primarily degraded by corrosion in untreated waters. Corrosion allowances, based upon very simplistic considerations of general corrosion in untreated raw water, were a part of the original design. However, long term service in many such systems has shown that localized corrosion phenomena, from microbiologically influenced corrosion, pitting, and underdeposit effects, have compromised system integrity. Because of the complexity and random nature of corrosion processes, it is nearly impossible to develop a mathematically deterministic model (like the typically used corrosion allowances) that accurately predicts pipe wall loss. However, when statistical distributions are used to describe the various corrosion processes, mathematical algorithms that incorporate all of the distributions, iterated a statistically significant number of times, can be used to forecast the most probable number of leaks. This approach was used to predict the condition of service water piping at a US Nuclear Power Plant, comparing results to service experience and inspection results. The results were ultimately used by the plant for targeting inspections and for long term planning of replacements and replacement schedules.
\end{abstract}

Keywords: nuclear power plants, service water systems, pitting, MIC, water treatments, probabilistic methods.

\section{Introduction}

The integrity and performance of nuclear plant service water systems, including service water piping, heat exchangers, pumps, and valves, is crucial to plant 
reliability and operation to 40 years and beyond. Service water piping systems will generally consist of large amounts $(1-20 \mathrm{~km})$ of various sizes $(20 \mathrm{~mm}$ to $1000 \mathrm{~mm}$ diameters) of piping, that provides cooling to all plant equipment, both safety related and non-safety related. In most cases, the service water system and condenser cooling water system use the same water source, except that the service water system will be everywhere in the plant and it will have pipe segments with much different flow histories than those of the condenser cooling water. As a result, the service water piping can experience very different corrosion mechanisms. The low temperature and low pressure piping systems, exposed to nominal operating conditions that typically would not be considered particularly challenging, are primarily degraded by corrosion. A typical corrosion allowance of 1 to $3 \mathrm{~mm}(0.025-0.0075 \mathrm{~mm} / \mathrm{y})$ for uncoated carbon steel piping was used for nuclear plants. Service water systems generally have attained 25-40 years of operating life without special attention. However, for extended life, some repair or replacement is expected. The keys to managing service water system degradation are to take appropriate mitigation actions early to avoid unforeseen failures or to do the required repair or replacement only once.

Service water piping is basically everywhere in the plant, with essentially no planned maintenance, so access can be difficult. All plants have experienced some level of service water system degradation, with some plants experiencing far greater degradation than had been anticipated during design. In those cases, the systems have required refurbishments, repairs, or replacements. Reported costs for local repairs for many plants have ranged from tens of thousands to hundreds of thousands of dollars (USD) per repair [1]. Full system replacements have been of the order of $\$ 30$ million.

Corrosion, fouling (macrofouling, microfouling, and sedimentation), and other effects that were detrimental to the reliability of the service water system and to the plant, led to the issue of Generic Letter 89-13 [2], which is a basic guideline for safety related service water systems at all U.S. nuclear plants.

During the 1980s and 1990s, a number of plants replaced small bore carbon steel lines with 300-series stainless steel due to tuberculation and occlusion. In some of these cases, the failure mode merely changed to pinhole leaks at welds (attributed to microbiologically influenced corrosion or MIC) in roughly the same or shorter time frame.

\section{Background}

Generic Letter 89-13 [2] was issued to address service water system degradation. All U.S. licensees were required to address those issues for their safety related service water system. The five main points of the generic letter are:

I. Implement and maintain an ongoing program of surveillance and control to significantly reduce the incidence of flow blockage problems as a result of biofouling

II. Verify the heat transfer capability of all safety-related heat exchangers 
III. Ensure by routine inspection and maintenance that corrosion, erosion, protective coating failure, silting, and biofouling cannot degrade performance

IV. Confirm service water system is consistent with licensing basis

V. Confirm maintenance practices, operating and emergency procedures, and training.

A key objective of a GL89-13 program is to provide methods for assessing the degree of degradation and for assuring that the system meets its design basis, including heat removal during and following an accident, throughout the life of the plant. The implementation of the Generic Letter is left up to the plant owner.

\subsection{Service water system design}

Typical design requirements for service water systems are very basic: the system must be capable of removing heat from plant equipment under all anticipated operating conditions, including design basis accident conditions. For safety related service water systems, those requirements generally necessitate that the system be sized to provide cooling under the high heat load conditions of an accident, even though normal heat loads will be far less. In addition, requirements for diverse and redundant heat removal capabilities typically require that two, sometimes three, separate and nearly identical service water trains exist. Those requirements guarantee that the flows will be low and that the service water system will spend large portions of its lifetime under stagnant conditions.

Differences among plant locations and system designers also make water chemistries, materials selections, and system design highly non-standardized.

In general, the service water system operates at all times, whenever irradiated fuel is on site; however, as noted above many parts of the service water system sit idle, full of water, for the majority of the system's life. This is especially true of safety related systems or trains, which only flow during system testing, maintenance, and in non-normal operating conditions.

Service water treatments range from no treatment at all to periodic shock doses of oxidizing biocides (e.g., for macrofouling organisms like clams and mussels), or to low level biocide treatments (continuous and periodic) for biofilms.

\subsection{Typical service water system performance}

As noted above, there is no such thing as a "typical" service water system. Still, service water system experience from a number of plants provides a useful illustration of the situation that all plants must manage. Figure 1 is a plot of the cumulative number of leaks from a safety related service water system at a US nuclear plant cooled by fresh water. That curve is typical of the classic "bathtub curve", except that the infant mortalities that define the early part of the curve are not included in Figure 1. Degradation processes that are cumulative over the life of a component or system will produce damage that begins to cause failure 


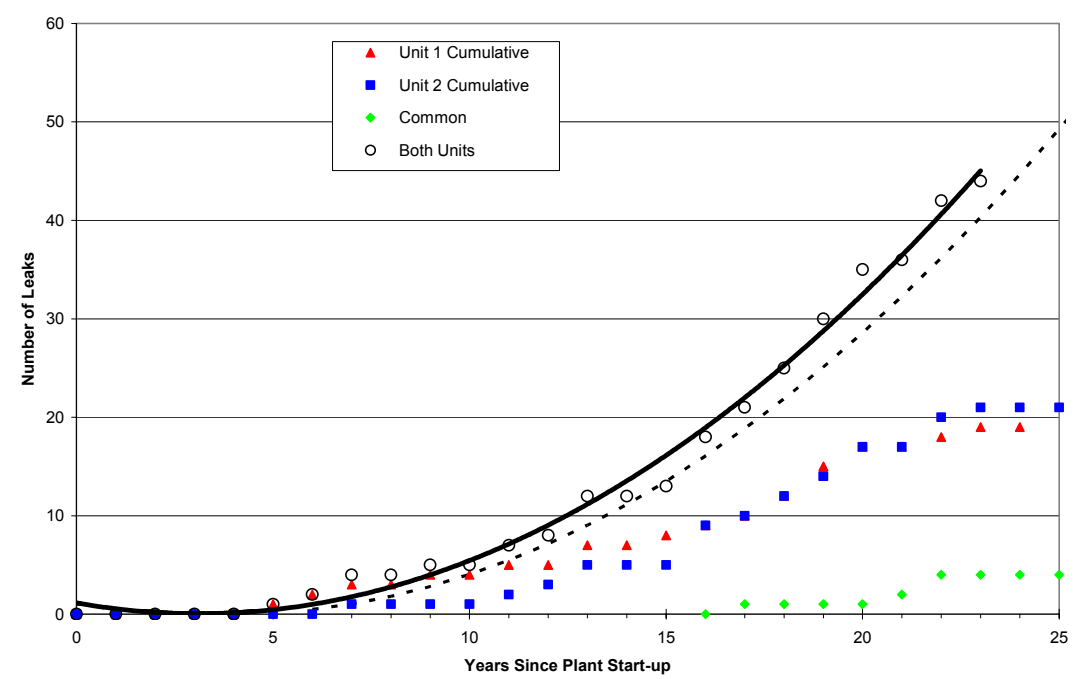

Figure 1: Leak history (cumulative).

or leaks at the areas where degradation is most rapid or acts over the longest time, while the bulk of the system remains leak free, even though it has incurred some amount (often a very small amount) of degradation.

Some plants have focused service water system programs on "dead legs", where low and intermittent flow conditions could lead to sedimentation, deposition of macrofouling and biofilms, and MIC. Others have attempted to select and regularly inspect areas that would be anticipated to experience worst case corrosion. Other plants have attempted to modify flow schedules or have spent significant amounts of money on chemical treatment programs. Some plants have managed fouling and heat transfer issues (Items I and II from the Generic Letter) well, but continue to experience corrosion issues in piping and in heat exchangers. The overriding factor in the selection of all approaches was to optimize component and system life and availability per unit cost.

\section{Approach}

For the example described in this paper, a review of the basic design information, inspections, history of failures and repairs, and replacements was conducted. The top level documents, such as the Service Water System Design Basis Document, all system flow diagrams, and isometric drawings were reviewed to extract pertinent information for qualitative and quantitative evaluations. The detailed inputs to the Internal Corrosion Model were compiled from the various drawings and other documents.

All flow diagrams and associated isometrics were reviewed to define line segments by their size, orientation, and flow history characteristics (e.g., fluid velocity, normally flowing, intermittent operation, normally stagnant, or dead 
leg). Other characteristics for line segments were assigned based upon safety significance, criticality to generation, etc. Those other characteristics were used to sort segments after corrosion susceptibility was determined to further prioritize pipe segments by their importance to safety, generation, or from other criteria. For example, if two lines have the same susceptibility but one is critical to generation, its priority is higher. Additional sorting and prioritization, based upon a system walkdown, can identify pipe segments and specific locations that may have greater importance because of their proximity to other critical equipment (e.g., safety related electrical cabinets).

\subsection{Degradation history}

In this example, the most commonly observed form of degradation had been sedimentation, typically in dead legs, intermittent flow legs, or slowly flowing legs. Some amount of corrosion, most often characterized by corrosion tubercles or nodules, had also been observed, however, the number of leaks was very small.

The plant's inspection program, initiated as part of its GL89-13 response, was focused mainly on occlusion due to tuberculation (from corrosion products), sedimentation, and macrofouling. It had been successful in characterizing occlusion from all forms as well as identifying some wall thinning.

The plant also recognized that as the service water system continues to age, wall thinning and the evolution of small leaks were likely to become more important. The purpose of the study described here was to evaluate the probable degree of degradation as a function of time and to permit improved decisionmaking regarding inspections (frequencies, methods), treatments, and long term strategies relative to inspections vs. repairs vs. replacements.

\section{Leak evolution predictions}

Corrosion is a stochastic process: even under closely controlled conditions nominally identical specimens exposed to nominally identical conditions will exhibit a distribution of corrosion rates and may exhibit varying degrees of different forms of corrosion. In a real system, especially a large system exposed to seasonal and other temporal variations in temperature, water chemistry, flow, and water treatment, it is nearly impossible to develop a mathematically deterministic model that adequately predicts corrosion rates incorporating all of those environmental and system variables. However, statistical distributions can be used to describe the various corrosion processes while mathematical algorithms, iterated a statistically significant number of times, can be used to predict the most probable number of leaks.

Structural Integrity developed a probabilistic leak prediction model that uses a Monte Carlo simulation using Latin Hyper Cube sampling. The piping system is broken into segments based on flow conditions and geometry. For each segment, the model incorporates probabilistic algorithms that describe general corrosion, pitting corrosion, and MIC to estimate the number of leaks that could 
be expected during a given time period. Other parameters derived from the predictions of metal loss are the probability of at least one leak and the number of segments predicted to have thinned to less than some value, such as the minimum design wall thickness, $\mathrm{t}_{\text {min }}$.

\subsection{Segment definition}

Each segment is defined by flow conditions and pipe geometry. Segments are composed of lines, where a line is defined by a contiguous section of pipe of a single size with no branches or changes in vertical orientation. That is, a number of lines; all fabricated from the same pipe size and with the same flow conditions, make up a segment. Flow conditions include the typical flow rate, the percentage of time that the segment flows, the number of days between flow, and any regular maintenance. Pipe geometry considerations included nominal size and schedule as well as orientation. Segments are thus not contiguous but are similar in terms of corrosion response. From the flow conditions and geometry, each segment was assigned a pitting and MIC index. Those indices identify a unique probability density from which a corrosion multiplier was chosen. The multiplier was applied to the probability distribution for general corrosion, producing a unique set of rates for general corrosion, pitting, and MIC for that segment.

The model breaks the total surface area of a segment into unit areas. The number of unit areas for a given piping segment is, therefore, a function of both pipe diameter and length. Probabilistically, a greater number of unit areas (greater surface area) will have a greater probability of a leak, given the same flow conditions. In low energy piping systems, leaks result as a section of pipe corrodes through wall as opposed to corroding partially through wall, then bursting or having the thinned segment "blow out". The approach can be applied to higher pressure systems, but additional considerations of pressure, affected area, orientation of the degraded area, etc. must also be considered.

Each segment will be made up of a single pipe size, and, thus, a single nominal wall thickness. Due to variations in manufacturing, the actual wall thickness is allowed to vary from the nominal by $12.5 \%$. The model chooses the initial wall thickness for each iteration based on a normal distribution with upper and lower limits of $12.5 \%$ of the nominal thickness.

\subsection{Corrosion rate determination}

In the model, an amount of wall loss is calculated for each pipe segment for each time step. The wall loss for a given segment is retained at the end of the time step and used as a baseline wall thickness for the next time step. When the total wall loss exceeds the original wall thickness, the model counts a leak. Therefore, the model predicts the distribution of the overall corrosion rate (i.e., general corrosion, pitting, and MIC) over the population. When the model is iterated thousands of times, the probability of a leak in the system over a given time frame can be determined. Using the same distribution slightly differently, the number of leaks (by segment, by pipe size, by flow condition, for the entire system, etc.) can be determined from that single series of computations. 
The Pisigan and Singley corrosion rate algorithm [3] is used to calculate a baseline general corrosion rate using various water chemistry inputs. The algorithm is strongly dependent upon dissolved oxygen content, water alkalinity, $\mathrm{pH}$, and chloride concentration. Pisigan and Singley's equation is useful for comparing the effects of different water chemistries on general corrosion, but the experimental program used to derive the algorithm was of short duration. As a result, the time dependence in the algorithm is less useful for long term predictions, and required adjustment based on benchmarking to available plant inspection data. For the plant evaluated in this example, the mildly scaling, slightly alkaline, cooling water resulted in a mean predicted general corrosion rate of $0.038 \mathrm{~mm} / \mathrm{year}$, which compared very well with the inspection data. The standard deviation was also calculated from available inspection data. These values were used to define a lognormal distribution for the general corrosion rate, which helps account for the uncertainty in the general corrosion rate. The level to which this can be accomplished is largely a function of the quality and quantity of available inspection data.

The difference between the general corrosion rate and the overall corrosion rate is that the overall rate considers general corrosion plus the contributions due to pitting and MIC. The pitting and MIC indices increase or decrease the influence of these degradation methods, and can have a significant impact on the results.

The pitting index was used to estimate pitting susceptibility on interior piping surfaces, with integer values ranging from 1 through 5 , where a value of 1 designates a low susceptibility to pitting and 5 is a high susceptibility. In the model, there are five discrete probability distributions, corresponding to the five possible pitting indices. The model chooses a value from the probability distribution and multiplies it by the general corrosion rate to determine the pitting rate.

The pitting index is based upon:

- History of corrosion-induced leaks due to internal pitting

- History of localized corrosion at the plant

- Water chemistry

- History of deposition (e.g., silt)

- Flow rate (low flow is worse)

- Percent of time flowing

- Stagnation time between flows.

The assignment of the pitting index is largely dependent on the experience of the analyst.

The MIC index is set up in the same way as the pitting index and is used in a similar manner in the model. The MIC index is also an integer from 1 through 5, where 1 designates a low susceptibility to MIC.

The MIC index is based upon:

- History of corrosion-induced leaks due to MIC

- History of MIC at the plant

- Microbiological deposits on piping or other surfaces 
- Piping geometry and its influence on flows

- Temperatures less than $66^{\circ} \mathrm{C}$

- Flow rate

- Percent of time flowing

- Stagnation time between flows.

As with the pitting index, assignment of the MIC index is dependent on the experience of the analyst.

Biocide treatment is the most commonly used approach to mitigate MIC. Biocide treatments can be very effective for MIC prevention, but are likely to be much less effective when applied to already fouled surfaces with established microbial colonies and/or nodules.

The MIC mitigation effectiveness index is an integer from 0 to 4 , where a 0 indicates no MIC mitigation and a 4 is the most completely effective MIC mitigation treatment. In the corrosion model, the biocide effectiveness index is subtracted from the MIC susceptibility index to select the probability distribution used to generate a multiplier on the general corrosion rate.

Since the corrosion model breaks time into discrete increments of five years, the variables can be altered to accommodate changes in operational procedure. For example, since the plant did not initiate a biocide program until 1990, the initial biocide effectiveness index was 0. After 1990, when the service water system experienced a daily addition of sodium hypochlorite, a biocide effectiveness level of 2 or 3 is used.

The addition of one or more corrosion inhibitors can provide a level of protection against both general corrosion and pitting, and is addressed by defining a corrosion inhibitor effectiveness multiplier. This multiplier is applied to the general corrosion, pitting, and MIC rates. The maximum and minimum values for the index are developed based upon industry recommended values for inhibitor concentration and the base water chemistry. In no case is an inhibitor effectiveness greater than $95 \%$. For the plant in this example, no corrosion inhibitor has been used, so this step was not required in the model.

The inputs to the corrosion model are listed in Table 1.

\section{Model results}

As described previously, the model defines (and counts) a leak when the wall loss accumulated over time exceeds the initial pipe thickness. As described above, the initial pipe thickness is chosen from a normal distribution with limits of plus or minus $12.5 \%$ of the nominal wall; the general corrosion mean and standard deviation are benchmarked against available inspection data; the general corrosion rate is chosen from a lognormal distribution with these parameters; the pitting and MIC indices define the distribution from which a multiplier on the mean general corrosion rate is chosen; and the effectiveness of treatments (if any) also produce a separate multiplier. Therefore, a leak will be a function of several probability distributions (initial wall thickness, general corrosion rate, pitting multiplier, and MIC multiplier). The model must be 
Table 1: $\quad$ Inputs to the Internal Corrosion Model.

\begin{tabular}{|c|c|}
\hline Variable & Description \\
\hline Length, feet & $\begin{array}{l}\text { Total length of piping in the segment (segment defined } \\
\text { by constant susceptibility conditions) }\end{array}$ \\
\hline $\begin{array}{l}\text { (Nominal) Wall } \\
\text { Thickness, inches }\end{array}$ & $\begin{array}{l}\text { Assumed to be normally distributed around the nominal } \\
\text { thickness }\end{array}$ \\
\hline $\begin{array}{l}\text { Wall Thickness } \\
\text { Tolerance, inches }\end{array}$ & Piping specs allow $12.5 \%$ variation \\
\hline $\begin{array}{l}\text { Inner Diameter, } \\
\text { inches }\end{array}$ & From applicable pipe schedule \\
\hline $\begin{array}{l}\text { Surface Area, } \\
\text { Inches }^{2}\end{array}$ & $\begin{array}{l}\text { Amount of pipe ID surface area is calculated from the } \\
\text { diameter and length inputs }\end{array}$ \\
\hline $\begin{array}{l}\text { Number of Unit } \\
\text { Areas }\end{array}$ & $=$ Surface Area/10,000 in $^{2}$ \\
\hline $\begin{array}{l}\text { Length of Service, } \\
\text { Years }\end{array}$ & $\begin{array}{l}\text { From initial wet-out ( } 5 \text {-year increments for the first } 40 \\
\text { years; } 10 \text { year segments after } 40 \text { years) }\end{array}$ \\
\hline $\begin{array}{l}\text { Pitting } \\
\text { Susceptibility } \\
\text { Index }\end{array}$ & Indices range from 1 to 5 , with 5 being most susceptible \\
\hline $\begin{array}{l}\text { MIC } \\
\text { Susceptibility } \\
\text { Index }\end{array}$ & Indices range from 1 to 5 , with 5 being most susceptible \\
\hline $\begin{array}{l}\text { Biocide } \\
\text { Effectiveness } \\
\text { Index }\end{array}$ & $\begin{array}{l}\text { Indices range from } 0 \text { to } 4 \text {, with } 0 \text { being ineffective and } 4 \\
\text { being the most effective }\end{array}$ \\
\hline $\begin{array}{l}\text { Inhibitor } \\
\text { Effectiveness }\end{array}$ & $\begin{array}{l}\text { A percentage value, from } 0 \text { to } 95 \% \text {, is input based upon } \\
\text { inhibitor, surface condition, inhibitor concentration, } \\
\text { other water chemistry parameters }\end{array}$ \\
\hline $\mathrm{pH} @ 25^{\circ} \mathrm{C}$ & 8.32 \\
\hline Conductivity & $294.3 \mu \mathrm{S} / \mathrm{cm}$ \\
\hline Chloride & $11.64 \mathrm{ppm}$ \\
\hline Silica (SiO2) & $0.985 \mathrm{ppm}$ \\
\hline Sulfate & $23.34 \mathrm{ppm}$ \\
\hline Sulfate & $37 \mathrm{ppm}$ \\
\hline Magnesium & $12.7 \mathrm{ppm}$ \\
\hline Sodium & $5.9 \mathrm{ppm}$ \\
\hline
\end{tabular}

iterated a statistically significant number of times to generate a probability of leakage curve. For each plant, a sensitivity study is conducted to identify the minimum number of iterations required. Typically, the model statistics change very little after 7,500 iterations.

The results from the corrosion model applied to the example plant are shown in Figures 2 and 3. Those results show that the mean number of leaks is essentially zero for the first 20 years of service, but that the probability of at least one leak and the mean number of leaks increase exponentially with time. In 


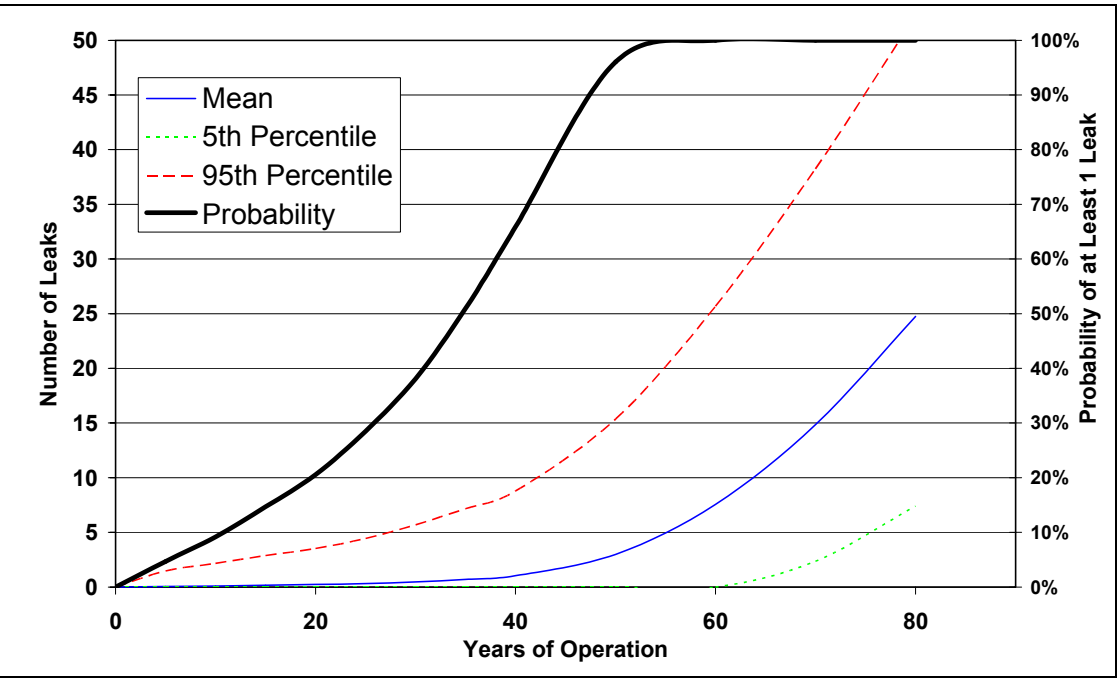

Figure 2: $\quad$ Corrosion Model results, life cycle management plot.

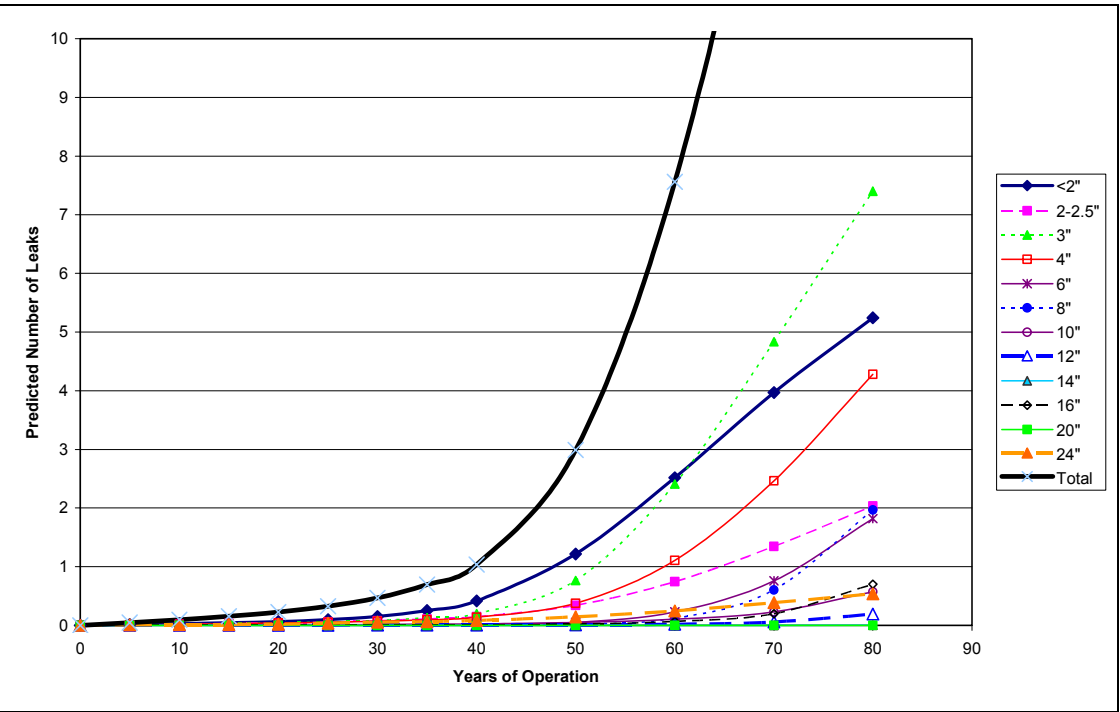

Figure 3: $\quad$ Corrosion Model results, effects of pipe size.

2007, the model predicted the mean number of leaks to be about one, but the worst case $\left(95^{\text {th }}\right.$ percentile case) shows roughly seven leaks. By 2034 (60 year life), the number of leaks is predicted to be between 7 (mean) and $26\left(95^{\text {th }}\right.$ percentile). 
Figure 4 shows how those same data can be used to target inspections as a function of pipe size, by creating a prediction of the mean number of leaks per length of pipe. The recommended number of inspection locations per pipe size is based on the relative contributions of the various pipe sizes, considerations of the predicted mean number of leaks per foot, and the relative importance of those lines. Susceptibility can (should) also be combined with consequences of a leak to define "risk".

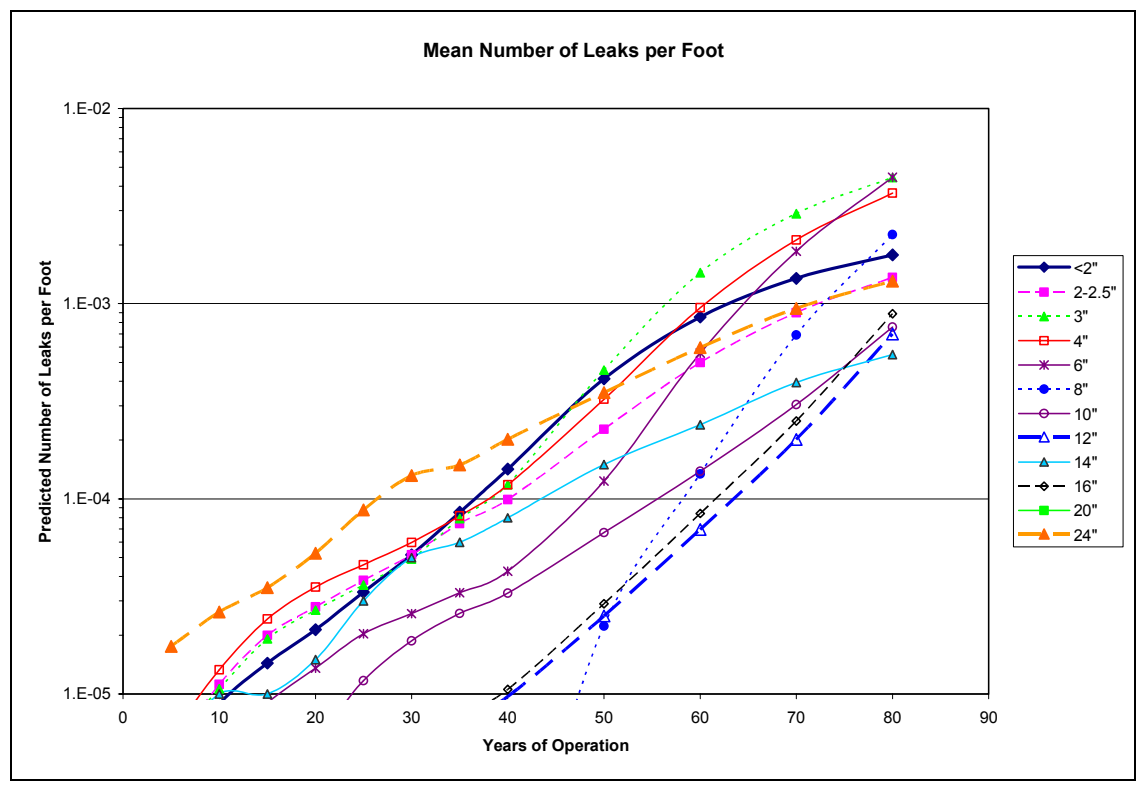

Figure 4: Corrosion Model results, predicted number of leaks per foot.

All of the predictions shown in Figure 2 through 4 were based upon the plant's current water chemistry and operating conditions. Modifications to operation or treatment would generally be expected to cause the predicted evolution of leaks to increase or decrease, based upon the nature of the change. For this plant, subsequent model runs with an "improved" biocide index showed that there was essentially no effect on the predicted mean number of leaks. This suggested that MIC has not been and is not expected to be a major contributor to the overall leak tightness of the piping at the plant, which was also consistent with observations of physical evidence to date.

\section{Improved model}

The tools used to carry out the analysis have evolved, but the basic process described in Section 4 remains essentially unchanged. The first model used Microsoft Excel exclusively, while later versions used Visual Basic for 
Applications (VBA) based plug-ins. The current model is a C\# based standalone program.

The original model utilized the random number generator and several of the basic statistical functions in Excel to sample the various probability distributions. Multiple iterations were run by manual recalculation. The Excel plug-in@RISK was used to automate the recalculation process, as well as provide limited statistical data on the output. Recently, the @ RISK program was used to define the majority of the distributions. In addition, @RISK tracked the convergence of selected outputs and incorporated Latin Hypercube sampling to reduce simulation runtime. This version of the corrosion model was used to predict the condition of the subject nuclear plant piping.

The current version of the corrosion model is a $\mathrm{CH}$ based standalone program as described below. Many of the features included in previous models to decrease run time are no longer necessary. Previous models employed a maximum of 10,000 model iterations with a runtime on the order of 15 minutes. The standalone program is capable of one million iterations in 15 seconds.

ACCORDION (ACcumulation of CORrosion Damage evolutION) computes the probability of corrosion damage as a function of time. It can consider a single piping segment or a complete system exposed to a varying water chemistry. ACCORDION can consider internal or external corrosion, or both. The inputs to ACCORDION include water chemistry, based on which the density function of corrosion rate is computed. The distribution of corrosion rate is further modified for the effects of pitting and MIC. The water chemistry input for each segment can vary with time.

ACCORDION computes the probability of leak or the probability of any fractional damage for each segment. It also computes the probability of damage for the whole system. It also ranks the segments based on the probability of corrosion damage, which is useful for making inspection/replacement decisions. ACCORDION also provides expected number of leaks for system as a function of time.

\section{Recommendations}

Plants that actually do inspect service water system piping as part of their GL8913 programs generally examine a relatively small number of points that represent a miniscule fraction of the entire system. The results of the model runs for this example, along with the incorporation of risk, can help to prioritize where to conduct inspections. Local detailed inspections, based upon model runs provide a far better sampling with the same number of inspections than the current program. For this example, the near term inspection matrix will emphasize 3", 4", 6", and 24" lines, along with a goal of sampling the smaller bore lines.

\section{Conclusions}

As noted in the GL 89-13 guidelines, keeping internal pipe surfaces clean and other good practices will help to maintain reliable operation over the initial 
40-year license term and provide the framework for programs to achieve extended operation. Use of Structural Integrity's statistically based model that incorporates the capability to assess general corrosion, pitting, crevice, corrosion, MIC, and the effects of varying flow and water treatment regimes, provides an additional and powerful tool to predict future condition and to direct and time additional programs to assure reliable performance past the 40 -year license term. Using the model permits plants to define where to inspect and when to incorporate service water system leaks a rare as opposed to such leaks becoming a much more common event as can occur where the knowledge to control leaks is not applied in a timely fashion.

\section{References}

[1] G.J. Licina, S.W. Borenstein, "Replacing, Refurbishing Nuclear Service Water Piping," Power, December 1993.

[2] "Service Water System Problems Affecting Safety-Related Equipment," Generic Letter 89-13, 7-18-89

[3] R.A. Pisigan and J.E. Singley, "Evaluation of water corrosivity using the Langelier index and relative corrosion models," NACE, 1985. 